\title{
Information disclosure in a local socio- economic system with tacit knowledge and information asymmetry
}

\author{
Alim Gurtuev ${ }^{1, *}$, Zaur Ivanov ${ }^{1}$, and Anzor Sabanchiev ${ }^{1}$ \\ ${ }^{1}$ Kabardino-Balkarian Scientific Center of the Russian Academy of Sciences, Institute for Computer \\ Science and Problems of Regional Management, I.Armand st., 37a, 360004, Nalchik, Russia
}

\begin{abstract}
We study the effects of institutional information disclosure on the market equilibrium in a local market with knowledge asymmetry and scarce information. The purpose of our work is the analysis of long-term efficiency of a dedicated institutional mechanism of information disclosure for such a market. The paper presents the game-theoretic model of a local property rights market with an infrastructural institution disclosing nonpersonalized information in a system with a combination of market elements, administrative and shadow economy. For each object, there is some hidden non-transferrable information essential for assessment. Under such conditions, the influence of subjective biases on the market equilibrium can be described as a Bayesian probability model of adverse selection. In the elaborated model, the equilibrium parameters are theoretically analyzed. It is shown that information asymmetry in the modeled systems leads to an irrational allocation of investment resources. It is shown that the infrastructural institutions disclosing non-personalized information are not only unable to efficiently counteract adverse selection, but facilitate it.
\end{abstract}

\section{Introduction}

The problem of inconsistency between the institutional environment and the market practice is especially acute at regional level. Researches show that regional officials may use the existing institutions to achieve their personal goals, which leads (as an externality) to dysfunctionality of these institutions [1-6].

When speaking of depressiveness of a region in the aspect of reproduction, usually the financial aspect of the problem is distinguished and the following characteristic features are listed [7-9]:

- Average annual investments are less than average annual capital consumption;

- Average annual net profit of enterprises after deduction of reimbursement to the owners and managers and liquidity reserve for current activity financing is less than average annual investments necessary for simple reproduction;

\footnotetext{
*Corresponding author: gurtuev@gmail.com
} 
- A large share of long-term unprofitable enterprises (over $30 \%$ of enterprises are unprofitable during 3 or more years).

Undoubtedly, the financial aspect is important for the assessment of a regional investment crisis; in particular, it allows objective comparison of different regional economies. At the same time, the institutional aspect of organization of the property rights market is no less important both for analysis and for elaborating efficient methods of investment process management in a region $[2,4]$.

Under institutional transformation characteristic for the economic systems of the Russian regions, new economic institutions are still rather weak, institutional frameworks expand under the influence of decisions of some market participants [10]. Deals formally signed between legal entities are actually signed between particular physical persons, while the mechanisms of transaction costs reduction are based on personal responsibility and customary law norms $[6,11]$. The result is the high level of information asymmetry in the property rights market. In particular, one should note the non-transparency of financial reporting of enterprises and the diffuse legal field. The latter consists, among other things, in expanding the practice of tax evasion with both "grey" and openly illegal means, economic inefficiency of complete formal observance of legal norms and the determinative role of customary law in insuring transactions $[12,13]$.

Although the existence and significance of the adverse selection effect are sometimes disputed in regard to certain markets [14-16], one may assert that the adverse selection effect is an objective feature of a market with informational asymmetry, which reduces the market mechanism efficiency [17-20].

In practice, one of the possible and rather obvious solutions to the problem of adverse selection in the property rights market in regional economy is creating special centralized institutions in the form of regional informational-investment centres in order to disclose the observed information and, as a result, increase the efficiency of a regional property rights market. Below we consider the methodological basis of regulating such market and analyze the efficiency of such mechanism of counteracting adverse selection under uncertainty.

\section{Materials and methods}

Numerous empirical data show that legal institutions influence the formation of business environment and, thereby, long-term economic growth. However, the specific mechanisms of such influence much less researched. Obviously, there are exceptions, like, for example, the correlation between organization of patent system and stimuli for innovative activity [21]. However, a number of other aspects, especially related to ensuring the contracts fulfillment, which is very important for the property rights market, are insufficiently studied.

As for the markets with imperfect information, a significant part of modern researches of economic agents' behavior in such markets can be divided into two main classes of tasks - the tasks with unobservable characteristics and unobservable actions. Distortions of efficient resources distribution under information asymmetry is proved in literature [18, 20, 22-24]. The examples are usually credit and insurance markets [25, 26], secondary markets of goods with unobservable characteristics [27, 28], and labor market [29-31]. The main object of analysis is the possible market response to asymmetrical information, as well as prerequisites for state intervention into economy with a view to correct the information failures of the market [32].

Under the circumstances, of particular interest is market functioning under uncertainty, when objective assessment of the object of a deal both on the part of a buyer and a seller is impossible due to the uncertainty of the future. So far, the main works in this sphere focused on researching the process of individual decision-making and modeling particular 
markets [33-35]. Limitedness of knowledge generates the problem of its asymmetry, while unlimited ability for processing information makes it possible to develop an optimal contract. This is an unduly strong assumption, leading to the impossibility to distinguish between the situations with knowledge asymmetry and those with information asymmetry.

The problem of pre-contract opportunism arises when solving the task of filtration the offers in the market in order to eliminate the deals knowingly disadvantageous for the buyer. The situation of pre-contract opportunism is most often described with the model of adverse selection $[14,16,19,22]$.

In the classical model of adverse selection, the conditions of one-time intersection of costs and utility must be fulfilled (concavity of the utility function and linearity of the cost function, or linearity of the utility function and convexity of the cost function). Thus, the condition of decrease of marginal utility of costs is fulfilled. Accordingly, in terms of attitude to risk, the only admissible variants are either risk aversion of the participant with informational advantage under risk-neutrality of the informational weak participant (concave utility function and linear cost function), or risk-neutrality of the participant with informational advantage and risk seeking of the informational weak participant (linear utility function and convex cost function). In case of asymmetrical knowledge, such a market will face mixing equilibrium, and the worst agents will have an advantage.

In the literature, there are models with an opposite assumption concerning the bargaining power of a participant with informational advantage [36]. In this situation, unlike in the models with zero bargaining power of a participant with informational advantage, either a single separating equilibrium or no equilibrium is possible. At that, the existence of a separating equilibrium depends on the distribution of participants with informational advantage by types. The existence of such equilibrium requires exceeding a certain critical share of participants with informational advantage of the lowest type, so that in the game of uninformed participants (representing Bertrand competition) Bayesian equilibrium is achieved.

At the stage of market research knowledge asymmetry acquires the form of hidden information, when the uninformed participant does not know the type of a participant with informational advantage, and at the stage of contract signing - the form of hidden actions, which occur when the uninformed participant does not know the preliminary costs of the participant with informational advantage, with whom the contract is signed. At the same time, it stems from the above definitions that these forms of knowledge asymmetry are also the forms of pre- and post-contract opportunism.

It should be noted that there is a great difference as to at which stage the problem is solved. If it is solved at the stage before signing the contract $[28,37]$, then it is an ex ante contract procedure. If it is solved at the stage of contract implementation, it is an ex post problem.

The existence of hidden knowledge is the most significant criterion for distinguishing between an uninformed agent and an agent with informational advantage, as it is knowledge asymmetry that is the source of problems occurring in their relations. In compliance with this criterion, the participant without knowledge is the party without with informational advantage, while the participant with advantage in knowledge is the party with informational advantage. This distinction bears a different meaning depending on the type of the models under consideration. In the adverse selection models, awareness refers to the type of the participant with informational advantage, in the sense that an uninformed participant does not know the type of a participant with informational advantage, while the participant with informational advantage knows both their own type and the type of their counteragent.

\section{Model and results}


Thus, let us consider a regional market of property rights with information asymmetry.

Let the value of investment object $\mathrm{v}$ (expressed via NPV) be $\mathrm{H}$ or $\mathrm{L}$, while $\mathrm{H}>\mathrm{L}$.

Let $\mathrm{H}$ be a high-quality goods, and $\mathrm{L}-\mathrm{a}$ low-quality one (for example, high crediting risks, inefficient management, lack of links - for the object of investment; risk of unfriendly actions of a creditor, financial instability - for the investor), similar to the "market for lemons" model [22].

A potential participant of the property rights market is either informed (knowing the value of $v$ ) or uninformed.

The uninformed participant believes that $\mathrm{v}=\mathrm{H}$ with probability $\mathrm{p}<1$, and $\mathrm{v}=\mathrm{L}$ with probability 1-p .

Let the Regional Investment Informational Center (further - RIIC) accumulate information about applications for selling and buying property rights (applications for credits and capital allocation, selling and buying enterprises and their shares) and does not influence the prices for applications (is financed from the state budget and acts so as its own profit is zero).

Here, RIIC can be considered as a market maker with zero profit.

RIIC does not know the value of $\mathrm{v}$ and has the same expectations as an uninformed participant.

Let us assume that all actual applications can be represented as a product of a minimal standard application (MSA) and some coefficient. This is done for convenience.

Let $\mathrm{B}$ be the price of demand, and A be the price of supply

Let $\mathrm{E}(\mathrm{v} \mid \mathrm{I})$ be the expected value of $\mathrm{v}$ according to information $\mathrm{I}$.

$$
E(v \mid I)=H p(v=H \mid I)+L p(v=L \mid I)
$$

where

$\mathrm{p}(\mathrm{v}=\mathrm{H} \mid \mathrm{I})$ is probability that $\mathrm{v}=\mathrm{H}$ according to information $\mathrm{I}$

$\mathrm{p}(\mathrm{v}=\mathrm{L} \mid \mathrm{I})$ is probability that $\mathrm{v}=\mathrm{L}$ according to information $\mathrm{I}$

If a participant wants to sell a share of an enterprise, constituting Q minimal standard applications, then RIIC “buys” them at a price B. RIIC's income is:

$$
Y_{c}=Q E\left(v \mid I_{R I I C}\right)-Q B
$$

where E(v| I_RIIC ) is the expected value of v according to information RIIC.

In this case, the condition of RIIC's zero profit can be written as:

$$
\left[B=E\left(v \mid I_{\text {sell }}\right)\right] \wedge\left[A=E\left(v \mid I_{\text {buy }}\right)\right]
$$

RIIC possesses information about deals but does not know if particular participants are informed or uninformed.

It can be assumed that RIIC believes that a participant is informed with probability $\mathrm{q}<1$ and uninformed with probability 1 -q.

Then it can be assumed that $\mathrm{q}$ is the share of informed participants among all participant of the property rights market.

We determine the price of supply A when an application for buying appears

$$
A=H p(v=H \mid b u y)+L p(v=L \mid b u y)
$$

According to Bayes law, from (1) we obtain: 


$$
\begin{aligned}
& p(v=H \mid \text { buy })=\frac{p(v=H) p(b u y \mid v=H)}{p(v=H) p(b u y \mid v=H)+p(v=L) p(b u y \mid v=L)} \\
& p(v=L \mid b u y)=\frac{p(v=L) p(b u y \mid v=L)}{p(v=H) p(b u y \mid v=H)+p(v=L) p(b u y \mid v=L)}
\end{aligned}
$$

Now we define what is the probability of appearing an application for buying $\mathrm{p}($ buy $\mid \mathrm{v}=\mathrm{H})$. We denote an informed participant as $i^{K}$, and uninformed as $i^{N}$. Then

$$
p(b u y \mid v=H)=p\left(i^{K}\right) p\left(i^{K} \text { buys } \mid v=H\right)+p\left(i^{N}\right) p\left(i^{N} b u y s \mid v=H\right)
$$

We denote as $\alpha$ the probability that the uninformed participant applies for buying, regardless of the value of $\mathrm{v}$ (as the uninformed participant does not know it).

Now we may write:

$$
p(b u y \mid v=H)=1 q+\alpha(1-q)=q+\alpha(1-q)
$$

Similarly for $\mathrm{p}($ buy $\mid \mathrm{v}=\mathrm{L})$ :

$$
p(b u y \mid v=L)=0 q+\alpha(1-q)=\alpha(1-q)
$$

We simplify the expressions, denoting $\mathrm{p}(\mathrm{v}=\mathrm{H})$ through $\mathrm{p}$, and $\mathrm{p}(\mathrm{v}=\mathrm{L})$ through 1-p , as there are only two types in the model. Putting the value obtained in (8) into (5), we get:

$$
p(v=H \mid b u y)=\frac{p(q+\alpha(1-q))}{p(q+\alpha(1-q))+\alpha(1-p)(1-q)}
$$

Hence

$$
p(v=H \mid b u y)=\frac{\alpha p+(1-\alpha) p q}{\alpha(1-q)+p q}
$$

Similarly, with a little algebra, we get:

$$
p(v=L \mid b u y)=\frac{\alpha(1-p)(1-q)}{\alpha(1-q)+p q}
$$

Consequently,

$$
A=E(v \mid b u y)=H\left(\frac{\alpha p+(1-\alpha) p q}{\alpha(1-q)+p q}\right)+L\left(\frac{\alpha(1-p)(1-q)}{\alpha(1-q)+p q}\right)
$$

As $\mathrm{q}>$ pq (because $\mathrm{p}, \mathrm{q}<1$ ), it follows:

$$
\begin{aligned}
& \frac{\alpha p+(1-\alpha) p q}{\alpha(1-q)+p q}=p\left(\frac{(q+(1-q) \alpha)}{p q+(1-q) \alpha}\right)>p, \\
& \text { as } \frac{(q+(1-q) \alpha)}{p q+(1-q) \alpha}>1
\end{aligned}
$$

Hence the optimal price for buying is

$$
A=E(v \mid b u y)>(p H+(1-p) L)
$$


Hence it follows that, as the expected value of $\mathrm{v}$ for the risk-neutral uninformed participants $E(v)=(p H+(1-p) L)$ is less than the optimal price of buying, they will not buy at all $(\alpha=0)$.

Thus, RIIC will have to set the buying price at

$$
A=E(v \mid b u y)=H
$$

The same is true for selling:

$$
E(v \mid \text { sell })=H p(v=H \mid \text { sell })+L p(v=L \mid \text { sell })
$$

According to Bayes law, we have:

$$
\begin{aligned}
& p(v=H \mid \text { sell })=\frac{p(v=H) p(\operatorname{sell} \mid v=H)}{p(v=H) p(\operatorname{sell} \mid v=H)+p(v=L) p(\operatorname{sell} \mid v=L)} \\
& p(v=L \mid \operatorname{sell})=\frac{p(v=L) p(\operatorname{sell} \mid v=L)}{p(v=H) p(\operatorname{sell} \mid v=H)+p(v=L) p(\operatorname{sell} \mid v=L)}
\end{aligned}
$$

We denote as $\gamma$ the probability that the uninformed participant applies for selling, regardless of the value of $v$ (not knowing it).

Hence we may write:

$$
B=E(v \mid \text { sell })=H\left(\frac{p \gamma(1-q)}{\gamma(1-q)+q(1-p)}\right)+L\left(\frac{(1-p)(q+\gamma(1-q))}{\gamma(1-q)+q(1-p)}\right)
$$

As $\frac{p \gamma(1-q)}{\gamma(1-q)+q(1-p)}<p$, then

$$
B=E(v \mid s e l l)<(p H+(1-p) L)
$$

Here we see that the expected value of $\mathrm{v}$ for uninformed participants $\mathrm{E}(\mathrm{v})=(\mathrm{pH}+(1$ p)L) $>B$, which makes selling irrational $(\gamma=0)$.

Thus, RIIC will have to set the selling price at $\mathrm{L}$.

Equilibrium in the market institutionalized in this way will be set under the following conditions:

The selling price $=\mathrm{L}$ (all property rights applied for selling are considered to be low quality).

The buying price $=\mathrm{H}$ (all property rights for which there are applications for buying are considered to be high quality).

There are no uninformed participants in the market (adverse selection).

\section{Conclusion and Discussion}

Uncertainty and information asymmetry in the property rights market, taking into account the specificity of economic systems of regions with shadow economy, lead to irrational allocation of investment resources.

Most of the decisions in such markets are based on assessment and uncertain reasoning. When assessing the future profit from the property rights object, a buyer has to take into account such uncertain parameters as informal restrictions in the market, transferability of informal relational contracts with key persons, and the probability of significant changes in 
the future. An essential feature of such markets is that the conditions under which participant make decisions are unique. This leads to the situation that the mechanisms used to regulate traditional competitive markets are often inapplicable here.

The proposed model demonstrates that centralization is a poor solution for the problem of adverse selection under uncertainty, when information asymmetry occurs not due to the expensive means of observing the significant information, but due to the absence of such means. In such markets, be it a property rights market in a region with shadow economy, or investing into innovative projects, or interaction of agents in a multilevel system with hidden information, or something else, the main reason for inefficiency of the interaction mechanisms is distortions of subjective assessments of the market participants. The model shows how deviations of the subjective probability assessment of distribution when forecasting the future events from the actual distribution may lead to the market collapse.

At that, introduction of a centralized infrastructural institution like RIIC to solve the problem of information provision and increase the efficiency of a regional property rights market does not counteract the adverse effects of information asymmetry. On the contrary, leading to the consolidation of the local markets into a single information space, it facilitates adverse selection and leads to equilibrium when property rights market does not exist.

The obtained result shows that the type of knowledge, in regard of which asymmetry exists, is determinative when elaborating the mechanisms of interaction organization between heterogeneous agents in social-economic systems with information asymmetry. The mechanisms that are effective under risk, when elimination of information incompleteness leads to forming an effective market, cannot be used efficiently in the conditions of uncertainty.

The research was supported by the Russian Foundation of Basic Research, grant No. 19-010-00376 A "Mechanisms for screening innovation projects on the basis of the analysis of tacit knowledge" and grant No. 20-010-00269A "A mechanism for mountainous regions development management on the basis of a the new architecture of local socio-economic systems".

\section{References}

1. A. Ades, R. Di Tella. AER, 89(4), 982-993. (1999); doi: 10.1257/aer.89.4.982

2. S. Becker, P. Egger, T. Seidel. Eur. J. Polit. Econ., 25(3), 300-310. (2009); doi: 10.1016/j.ejpoleco.2008.12.002

3. A. Del Monte, E. Papagni. Eur. J. Polit. Econ., 23(2), 379-396. (2007); doi: 10.1016/j.ejpoleco.2006.03.004

4. R. Gillanders, S. Parviainen. Rev. Development Econ., 22(4), 1729-1743. (2018); doi: 10.1111 /rode. 12517

5. B. Neudorfer, N. Neudorfer. J. of Federalism, 45(1), 24-50. (2015); doi: 10.1093/publius/pju035

6. O. Pushkarev. Appl. Econometrics, 6(2), 81-94. (2007); http://pe.cemi.rssi.ru/pe_2007_2_81-94.pdf

7. Y. Aimagambetov, Y. Z̆hailauov. J. Adv. Res. Law and Econ., 8(1), 305-311. (2017); https://ideas.repec.org/a/srs/jarle0/v8y2017i1p305-311.html

8. H. Breinlich, G. Ottaviano, J. Temple. Handbook of Economic Growth, 2, 683-779 (2014); doi: 10.1016/B978-0-444-53540-5.00004-5

9. V. Spiezia, S. Weiler. Rev. Reg. Studies, 37(3), 344-366. (2007); doi: https://ideas.repec.org/a/rre/publsh/v37y2007i3p344-66.html 
10. T. Makhmudov, M. Konovalova, O. Kuzmina, N. Persteneva. Acta Oecon., 68(1), 115133. (2018); doi: 10.1556/032.2018.68.1.6

11. G. B. Kleyner. Voprosy ekonomiki, 4, 28-34 (1996)

12. V. Gimpelson, R. Kapeliushnikov. IZA Disc. Papers, 8279. (2014); http://ftp.iza.org/dp8279.pdf

13. S. Barsukova, V. Radaev. Econ. Sociology, 13(2), 4-12. (2012); https://ecsoc.hse.ru/en/2012-13-2/55582454.html

14. B. Handel, I. Hendel, M. D. Whinston. Econometrica, 83(4), 1261-1313. (2015); doi: 10.3982/ECTA12480

15. S. P. Hegde, J. McDermott. J. Bus. Fin. \& Acc., 31(7-8), 1097-1124. (2004); doi: $10.1111 / \mathrm{j} .0306-686$ X.2004.00568.x

16. G. Lewis. AER, 101(4), 1535-1546. (2011); doi: 10.1257/aer.101.4.1535

17. A. Edmans, I. Goldstein, W. Jiang. AER, 105(12), 3766-3797. (2015); doi: 10.1257/aer.20141271

18. M. B. Hackmann, J. T. Kolstad, A. E. Kowalski. AER, 105(3), 1030-1066. (2015); doi: 10.1257/aer.20130758

19. P. Kurlat. AER, 103(4), 1463-1489. (2013); doi: 10.1257/aer.103.4.1463

20. S. Morris, Hyun Song Shin. AEJ: Macroeconomics, 4(1), 1-21. (2012); doi: 10.1257/mac.4.1.1

21. M. Seitz, M. Watzinger. Research Policy, 46(1), 182-195. (2017); doi: 10.1016/j.respol.2016.09.015

22. G. Akerlof. QJE, 84(3), 488-500. (1970); doi: 10.2307/1879425

23. N. Netzer, F. Scheuer. NBER. WP No.w18471. (2012); doi: 10.3386/w18471

24. M. Spence. QJE, 87(3), 355-374. (1973); doi: 10.2307/1882010

25. E. Fama. JPE, 88(2), 288-307. (1980); doi: 10.1086/260866

26. A. Finkelstein, K. McGarry. AER, 96(4), 938-958. (2006); doi: 10.1257/aer.96.4.938

27. R. Garcia-Flores, X. Z. Wang, G. E. Goltz. Comp. \& Chem. Eng., 24(2-7), 1135-1141. (2000); doi: 10.1016/S0098-1354(00)00494-4

28. B. Greenwald, J. Stiglitz, A. Weiss. AER, 74(2), 194-199. (1984); https://www.jstor.org/stable/1816354

29. Cho In-Koo, D. Kreps. QJE, 102(2), 179-221 (1987); doi: 10.2307/1885060

30. A. Denzau, M. Munger. Am. Polit. Sci. Rev., 80, 89-106. (1986); doi: $10.2307 / 1957085$

31. F. Docquier, A. Marfouk. World Bank Policy Research WP, n. 3382. (2004); https://ideas.repec.org/p/ctl/louvec/2007045.html

32. W. Fuchs, A. Skrzypacz. J. Econ. Theory, 158, 371-406. (2015); doi: $10.1016 /$ j.jet.2015.04.009

33. K. Jurado, S.C. Ludvigson, S. Ng. AER, 105(3), 1177-1216. (2015); doi: 10.1257/aer.20131193

34. K. Saito. AER, 105(3), 1246-1271. (2015); doi: 10.1257/aer.20131030

35. E. Shmaya, L. Yariv. AER, 106(7), 1775-1801. (2016); doi: 10.1257/aer.20120978

36. A. Gurtuev, E. Derkach, Z. Ivanov. Izvestiya KBNC RAN, 5(73), 62-68. (2016)

37. A. Gurtuev. MATEC Web Conf., 226, 04032. (2018); doi: $10.1051 /$ matecconf $/ 201822604032$ 